\title{
El K-pop de BTS, exponente del Hallyu, del Poder Blando y de la Comunicación Transmedia
}

\author{
Leonor Cremayer Mejía ${ }^{1 *}$
}

\begin{abstract}
Resumen
El fenómeno denominado Hallyu es promovido por diversos productos de entretenimiento producidos en Corea del Sur y difundidos a través de medios alojados en la red. El K-pop es un poderoso motor internacional del Hallyu y ha llevado a sugerir que esta tendencia es parte de una estrategia gubernamental denominada "poder blando" que el país asiático emprendió para fortalecer su imagen ante el mundo. En los últimos dos años, el grupo musical BTS se consolidó como una fórmula de comunicación transmedia destacada, por lo cual documentar el caso con base en investigación y análisis es pertinente para los estudios contemporáneos de comunicación.

\section{Abstract}

The phenomenon called Hallyu is promoted by several entertainment products produced in South Korea and disseminated through media hosted on the internet. K-pop is a powerful international engine of Hallyu and has led to suggest that this trend is part of a government strategy called soft power that the Asian country undertook to strengthen its image to the world. In the last two years, the boy band BTS has consolidated itself as the most outstanding transmedia communication formula, so documenting the case based on research and analysis is relevant for contemporary communication studies.
\end{abstract}

\section{Palabras Clave}

Hallyu, Poder blando, Transmedia, K-pop, BTS

Keywords

Hallyu, Soft power, Transmedia, K-pop, BTS

${ }^{1}$ Maestra en Educación Superior. Universidad La Salle Ciudad de México

*Autor para correspondencia: Icremayer@yahoo.com.mx

\section{Introducción}

Con el propósito de tener un acercamiento al tema se realizó una investigación preliminar para delinear el estado de arte sobre el fenómeno provocado por los productos de entretenimiento creados en Corea del Sur. El resultado mostró que el tema se ha estudiado y documentado desde diversos ángulos, en forma recurrente desde el político, económico, cultural y turístico. A pesar de lo anterior, no se ubicó una comunidad en el campo de la comunicación que diserte de manera formal y continua sobre el tema. En la información revisada se localizaron tres nociones nodales que se consideraron viables para explicar este fenómeno cultural y de comunicación internacional: Hallyu, teoría del poder blando y comunicación transmedia. Las tres se documentaron y recuperaron para el proceso de este análisis. El caso BTS fue elegido por ser un grupo de impacto importante, puesto que las cifras lo colocan en un lugar sin precedente en la historia del K-pop en los últimos dos años; con él se pueden explicar y ejemplificar los conceptos Hallyu y poder blando.

Las metodologías de estudio que se emplearon para el análisis fueron: investigación documental en archivos bibliográficos, bases de datos, videos, páginas de internet y plataformas de redes sociales. También se aplicó un análisis al caso de estudio con base en una plantilla para el diseño 
de narrativas transmedia. Los elementos propuestos en la plantilla que presentaron viabilidad y pertinencia, se adaptaron a manera de categorías para ejecutar el análisis.

\section{Qué es el Hallyu, cómo se construye y esbozos de su impacto}

Hallyu se traduce como "onda u ola coreana", se pronuncia hal-lyu. Hallyu es: “el fenómeno mundial del entretenimiento coreano y la cultura popular que se extiende por todo el mundo, a través de la música $K$-pop, dramas coreanos, programas de televisión y películas" (Kang, 2016, p. 60).

Como señala Vargas (2015):

El término Hallyu fue introducido por primera vez por los medios de comunicación chinos para describir el auge del entretenimiento coreano en China a finales de 1990 (Kim \& Ryoo, 2007). Originalmente centrado en dramas de televisión, música pop y sus estrellas, el significado del término se ha ampliado para incluir la popularidad de cualquier cosa de origen coreano (Kim \& Ryoo, 2007). Entre 2001 y 2010, el ingreso anual total de las exportaciones de contenido cultural de Corea aumentó de 12 a 172 millones de dólares (Chang, 2012). De acuerdo a Google Trends, el video Gangnam Style de Psy fue buscado desde una amplia gama de países, incluyendo Turquía, Sri Lanka, Líbano y Honduras. La música pop coreana se ha convertido en una parte importante de los "contra flujos" o "medios de comunicación subalternos" (Kim et al, 2013; Thussu, 2010) que hacen referencia a redes de contenidos que emanan de centros regionales de creatividad que no son estadounidenses o británicos (Vargas, 2015, p. 125).

El texto Repercusiones Sociales de género de la Ola Coreana (Hallyu) ofrece la siguiente idea:

Esta visibilidad cultural y su creciente éxito internacional recibe el nombre de Hallyu (한
류) u ola coreana, la cual supone un marco sin precedentes para la cultura coreana, que cuenta ahora con el impulso de los medios de comunicación coreanos, sumado al nuevo nacionalismo comercial. Como resultado la ola coreana se manifiesta como una tendencia cultural regional que supone un triunfo para la cultura coreana (Simón, 2015, p. 3).

El consumo de contenidos y la intensa interacción de los fans a través de la red son sustanciales para Hallyu; el resultado es un llamativo interés, casi una manía, por apropiarse de algunas manifestaciones de la cultura surcoreana, entre ellas: comida, bebidas, maquillaje, moda e idioma. Inclusive, ahora Corea del Sur figura como un atractivo destino turístico y de intercambio académico ${ }^{1}$.

A continuación, un fragmento del discurso pronunciado por el actor surcoreano Lee Min Ho en la apertura del evento KCON Los Ángeles, California 2016:

La cultura es la fuerza que mantiene al mundo unido. A través de la música, dramas y películas trasmitimos nuestros pensamientos. Con ese poder nos acercamos los unos a los otros, en el centro está el Hallyu. A donde quiera que vayas en el mundo podrás ver el Hallyu propagándose a lo largo y ancho, esto es a través del $K C O N$. Desde el 2012 KCON ha crecido inmensamente a lo largo de cinco años y cada año que pasa el Hallyu ha unido a más y más personas. Un festival para disfrutar juntos, con alegría y grandes emociones. Un lugar donde los sueños se hacen realidad ¿no es increíble? Y esta noche más brillante e impresionante que nunca, $\mathrm{KCON}$ 2016 Los Ángeles aparecerá frente a sus ojos, ahora, justo aquí. $K C O N$ ha tenido un papel fundamental en acercar al mundo a la cultura coreana por cinco años. Gracias a todos por su incondicional amor y atención. Como un actor de televisión y películas soy capaz de llegar a

\footnotetext{
${ }^{1}$ Actualmente una estudiante de la licenciatura en Ciencias de la Comunicación de la Universidad La Salle Ciudad de México está viviendo la experiencia de intercambio académico en la Hankuk University of Foreign Studies. Una de las asignaturas que cursa es Korean Popular Culture and Hallyu.
} 
personas de todo el mundo y ver cuánto disfrutan de Corea. Quiero agradecerles nuevamente a todos por brindar su atención a la cultura coreana, gracias, sus aclamaciones dan mucha energía a los artistas del K-pop (Official, 2016).

En resumen, los rasgos distintivos del Hallyu se centran en que:

1. Es un fenómeno de cultura popular de impacto internacional.

2. Se compone de música (K-pop) y narrativas audiovisuales (K-Drama ${ }^{2}$ y una parte de la producción cinematográfica $\left.{ }^{3}\right)$.

3. Sus recursos de difusión son los medios alojados en la red.

4. Sus fans son numerosos, diversos e internacionales; su papel en la difusión del Hallyu es básico porque ellos, a través de las diferentes plataformas y redes sociales, dan vida y alimentan la proliferación del fenómeno.

5. El Hallyu es un proyecto gubernamental que busca fortalecer y posicionar la imagen del país y con ello abrir mercados; a esa acción se le ha dado el nombre de poder blando.

\section{La teoría del poder blando detrás del Hallyu}

Manuel R. Torres Soriano ${ }^{4}$ (2005) identifica que hay una nueva lógica geopolítica que obvia la universalización de las nuevas tecnologías de comunicación e información y la necesidad de una sociedad interconectada y con capacidad de acceder a cantidades descomunales de información. Torres señala que Joseph Nye, geopolitólogo norteamericano, se acercó a interpretar este escenario al proponer el término soft power (poder blando).

\footnotetext{
${ }^{2}$ Es frecuente que al $K$-Drama se le confunda con el Dorama o se le llame telenovela surcoreana. Dorama es un término utilizado para denominar a las (series) narrativas audiovisuales japonesas. Usar el concepto novela surcoreana es erróneo, no existe tal denominación desde la concepción del entretenimiento de ese país.

${ }^{3}$ Corea del Sur produce cine comercial, pero también tiene una importante industria cinematográfica de tradición en Asia y en el mundo. Uno de los festivales más emblemáticos que se celebran en Corea del Sur, es el Festival de Cine de Busan.

${ }^{4}$ Catedrático de Ciencia Política en la Universidad Pablo de Olavide en Sevilla. Investigador del Departamento de Ciencia Política y de la Administración de la Universidad de Granada y Visiting Fellow en la Universidad de Stanford.
}

En palabras de Nye,

El poder blando de un país descansa principalmente en tres recursos: su cultura (en lugares atractivos para otros), sus valores políticos (cuando cumplen expectativas dentro y fuera), y sus políticas extranjeras (cuando son vistas como legítimas y con autoridad moral) ... Cuando la cultura de un país incluye valores universales y sus políticas promueven valores e intereses que otros comparten, aumenta la probabilidad de obtener los resultados deseados debido a las relaciones de atracción y deber que crean (Nye, 2004, p. 11).

Torres recupera las palabras de Nye y hace la siguiente interpretación:

Para este académico norteamericano su concepto se puede sintetizar en la capacidad de "lograr que otros ambicionen lo que uno ambiciona". Joseph Nye elabora su concepto en contraposición a la concepción tradicional sobre el poder o poder duro (hard power), aquella visión que apuntaba a la fuerza militar, la capacidad económica y las potencialidades que se derivan de ellos como la expresión más genuina del poder de un Estado (Torres, 2005, p. 3).

Ante la referencia anterior que define al poder de forma material con elementos cuantificables que usualmente provienen de la iniciativa política y están supeditados a su control directo, Nye visualiza otra lista de factores no materiales, no controlados por el soporte gubernamental y que tienen el poder de abonar tanto o más que la presión militar y la restricción económica, a la conquista de las metas marcadas por una nación.

Torres ahonda en las implicaciones de la propuesta Nye,

La popularidad de la producción artística, musical y cinematográfica de un país, su prestigio científico y educativo, su atractivo turístico, su capacidad para exportar modas y tendencias, la calidad de vida, su gastronomía, etc., son elementos cuya capacidad de movilización de voluntades sigue una línea ascendente. Se trata 
de una forma indirecta de ejercer el poder donde: "Un país puede obtener los resultados que desea porque otros países quieran seguir su estela, admirando sus valores, emulando su ejemplo, aspirando a su nivel de prosperidad y apertura" (Torres, 2005, p. 3).

Más que solo la consecuencia de una acción gubernamental oficial, el poder blando es un subproducto social y económico, su esencia se encuentra en la unión de múltiples actores que, a través de sus acciones, logran crear un producto con resultados provechosos que impactan a la sociedad. En este sentido, el sistema democrático es un terreno fértil para el poder blando. Los países que tienen posibilidad de desarrollar esta clase de competencias son:

Aquellos cuya cultura e ideas se hallan más próximos a las normas globales, aquellos que dispongan de mayor acceso a los canales de comunicación y aquellos que posean una credibilidad creciente gracias a sus actuaciones tanto en asuntos domésticos como internacionales. El prestigio se convierte en un elemento trascendental para que cada Estado pueda lograr sus objetivos. La política se convierte en un concurso de credibilidad competitiva, los gobiernos compiten entre sí y con toda otra serie de actores políticos para aumentar su credibilidad y debilitar la de sus adversarios (Torres, 2005, p. 4).

Nye es autocrítico con su teoría, identifica que hay un nivel de idealismo en ella y que su noción de poder es una tendencia a futuro que actualmente debe previvir y perfeccionarse al lado de agobiantes manifestaciones del poder duro.

Algunos escépticos objetan la idea del poder blando porque piensan en el poder estrictamente en términos de control activo. En su opinión, la imitación o la atracción son simplemente eso. Como hemos visto, cierta atracción imitativa no produce mucho poder sobre los resultados de las políticas, y tampoco la imitación siempre produce resultados deseables[... es importante especificar las condiciones bajo las cuales es más probable que la atracción conduzca a los resultados deseados y bajo cuáles no [...] es probable que la cultura popular atraiga a la gente y produzca poder blando en el sentido de los resultados deseados en situaciones en las que la cultura es algo similar en lugar de diversa [...] Todo poder depende del contexto, quién se relaciona con quién y bajo qué circunstancias; el poder blando depende más que el poder duro, de la existencia de intérpretes y receptores dispuestos. Además, la atracción a menudo tiene un efecto difuso, creando influencia general en lugar de producir una acción específica fácilmente observable (Nye, 2004, p. 15-16).

El concepto de poder blando se vincula con la creciente importancia de los flujos de información, la opinión pública en el contexto internacional y los contenidos no materiales en juego de la política.

La conclusión de Torres sobre la teoría de Nye,

Se trata de elementos que han servido de base para numerosas reflexiones teóricas, desde aquellas que contemplan una nueva forma de hacer política basada en la primacía de los valores, la ética y la actuación en redes, hasta los que consideran la difusión de códigos culturales y contenidos de información la principal expresión del ejercicio del poder (Torres, 2005, p. 5).

El principal cuestionamiento a esta teoría se inclina a considerar que el poder blando no es una forma de poder sino solo una percepción de la población sobre la legalidad de un recurso de poder, de tal forma que una intervención armada puede percibirse como blanda o suave si hay una aprobación generalizada sobre sus motivaciones y pertinencia. Esta última reflexión abre preguntas para otro estudio.

A manera de cierre, a continuación una cita con la opinión y análisis que la internacionalista Ana Velasco ${ }^{5}$ realizó para una cápsula de Noticieros Televisa:

Desde 2005 el gobierno surcoreano ha respaldado económicamente la expansión de su industria

\footnotetext{
${ }^{5}$ Comentarista en Noticieros Televisa, en el espacio de Foro TV.
} 
cultural en el extranjero como un vehículo para su poder blando (soft power). El poder blando o suave es la habilidad de un país para persuadir o influir en otros países sin necesidad de utilizar coerción o fuerza económica o militar y mejorar su imagen (Televisa, 2018).

\section{Comunicación transmedia y una plantilla para el diseño/análisis de narrativas}

Los grupos sociales siempre han manifestado interés por expresar y transmitir lo que sucede a su alrededor. Entre los recursos para hacerlo y las formas de mediación que utilizan, están las narrativas, por ejemplo: la tradición oral (voz a voz); los medios masivos de comunicación (uno a muchos) y las producciones digitales (uno a uno). La búsqueda principal ha sido conseguir mayor difusión, reconocimiento y lealtad para los relatos, así sea recreando la realidad o construyendo mundos imaginarios.

Dado que este análisis se centra en las narrativas transmedia (NT), se recuperó a Lev Manocvich quien define los principios estructurales que caracterizan a las narrativas en medios digitales desde la perspectiva de modularidad o estructura fractal.

Los elementos mediáticos, ya sean imágenes, sonidos, formas o comportamientos, son representados como colecciones de muestras discretas (pixeles, polígonos, vóxeles, caracteres o scripts) unos elementos que se agrupan en objetos de mayor escala, pero que siguen manteniendo sus identidades por separado. Los propios objetos pueden combinarse a su vez dando lugar a objetos aún más grandes; sin perder, ellos tampoco, su independencia (Manocvich, 2005, p. 75-76).

Se aduce a un sistema formal distinto que trabaja con su particular lógica espacio-tiempo que lo aleja de los medios tradicionales donde el vínculo entre las partes mantiene relación y secuencia. En las narrativas transmedia las partes son autónomas pero tienen la posibilidad de agruparse varias veces de diferentes formas, pueden transcodificarse, es decir, se pueden presentar como un tipo menú que se vincula con otro y otro y otro, lo que permite replicar, a gran escala, los estilos de presentación, representación y expresión.

Es precisamente la narrativa de origen digital lo que ha favorecido el desarrollo de narrativas que transitan de unas a otras con diferentes formatos, en diferentes plataformas de manera sencilla y rápida. En su texto Las características de las narrativas transmedia, Sandra Ruíz dice lo siguiente sobre este tipo de narrativas:

De esta multiplicidad de posibilidades que ofrece la estructura digital surgen narrativas como la transmedia, que efectivamente se refiere a un tipo de construcción narrativa que sólo se puede dar a partir de estas características de lo digital, donde hay una historia única autónoma que se cuenta a partir de partes o entradas también autónomas, generadas en diferentes medios, lenguajes o plataformas, pero que se relacionan entre sí.

Una historia transmedia se desarrolla a través de múltiples soportes mediáticos, con cada nuevo texto contribuyendo de manera distinta y valiosa para el todo. En la forma ideal de narrativa transmedia, cada medio hace lo que hace mejor, a fin que una historia pueda ser introducida en una película, ser expandida para la televisión, novelas y HQ; su universo pueda ser explorado en videojuegos o experimentado como atracción de un parque de diversiones (Ruíz, 2014, p. 100).

Por su parte, Scolari (2013) aporta las siguientes ideas sobre el mismo concepto:

Las NT son una particular forma narrativa que se expande a través de diferentes sistemas de significación (verbal, icónico, audiovisual, interactivo, etc.) y medios (cine, cómic, televisión, videojuegos, teatro, etc.). Las NT no son simplemente una adaptación de un lenguaje a otro: la historia que cuenta el cómic no es la misma que aparece en la pantalla del cine o en la microsuperficie del dispositivo móvil. Una estrategia tradicional de las empresas de comunicación se basaba precisamente en desarrollar la misma historia en diferentes medios 
o lenguajes [...] Cuando se hace referencia a las NT no estamos hablando de una adaptación de un lenguaje a otro (por ejemplo, del libro al cine), sino de una estrategia que va mucho más allá y desarrolla un mundo narrativo que abarca diferentes medios y lenguajes. De esta manera el relato se expande, aparecen nuevos personajes o situaciones que traspasan las fronteras del universo de ficción. Esta dispersión textual que encuentra en lo narrativo su hilo conductor - aunque sería más adecuado hablar de una red de personajes y situaciones que conforman un mundo- es una de las más importantes fuentes de complejidad de la cultura de masas contemporánea (Scolari, 2013, pp. 24-25).

Volviendo a Ruiz,

"Las partes que constituyen la narrativa transmedia no son definidas por la temporalidad o ubicación de cada acción. De hecho, las partes son definidas por las cualidades narrativas" (2012). Es decir, que cada parte da cuenta de la historia principal de manera independiente, sin ser igual a ella, ni contar todo. Cada parte puede ser entendida de manera aislada, pero es claro que forma parte de más historias sobre las cuales se despertará la curiosidad (Ruíz, 2014, p- 100).

La dinámica de las narrativas transmedia no se da de manera lineal donde una sección da sentido a la que le sigue, mejor dicho se trata de secciones narrativas independientes que cambian y se transcodifican según las entradas que no únicamente se generan por la decisión de quien crea el estructura formal digital, sino que entra en juego la otra característica sustancial de la narrativa transmedia, es decir, la interacción y participación en la creación narrativas de las diferentes audiencias o prosumidores. La narrativa transmedia posee una fuerza concurrente de medios que está disponible al convenio colaborativo donde las audiencias están en poder de expresar sus preguntas y contribuyen a la construcción y difusión de las narrativas.

Con la llegada de los nuevos medios se potencializó el desarrollo de la comunicación uno a uno. De esta premisa es que resultó pertinente abordar que los medios en red han sido la principal vía por la cual el $K$-pop ofrece narrativas transmedia para apoyar el fenómeno Hallyu y a su vez consolidar de manera paulatina la noción de poder blando en beneficio de la imagen del Corea del Sur.

Para realizar el análisis del caso BTS se recuperó una plantilla para la construcción de narrativas transmedia, la propuesta fue hecha en el año 2017 por Anahí Lovato ${ }^{6}$ y está conformada por la siguiente estructura: componentes de la historia, diseño de experiencia de los usuarios, determinación de las plataformas apropiadas para el storytelling ${ }^{7}$ y recursos requeridos para la ejecución.

El proyecto resultó de una serie de experiencias transmedia llevadas a cabo por el equipo de la Dirección de Comunicación Multimedial de la Universidad Nacional de Rosario y el material se presentó en el $9^{\circ}$ Foro Internacional de Periodismo Digital y el $4^{o}$ Encuentro de Narrativas Transmedia en Rosario, Argentina. La Tabla 1 refleja la plantilla para el diseño de narrativas transmedia. Con base en esta propuesta se seleccionaron las categorías pertinentes para realizar el análisis del caso BTS y su narrativa transmedia.

\section{El K-pop y el proyecto BTS}

La estructura del espectáculo surcoreano está integrada por varios elementos, entre los más importantes se encuentran las empresas de radio y televisión públicas y privadas $(K B S$, $S B S, M B C)^{8}$; las agencias de talentos (JYP, SM Entertainment, $Y G$ Entertainment $)^{9}$; las marcas surcoreanas de maquillaje, comida, tecnología y automóviles; el conglomerado Lotte ${ }^{10}$; $\mathrm{y}$, por supuesto, el apoyo gubernamental para favorecer la difusión de contenidos dentro y fuera de Corea del Sur. Las agencias de talentos y las empresas de medios son clave en el proceso creativo de producción y difusión de grupos y estrellas. En 2015 el K-pop significó, según la Agencia para la Promoción del Comercio e Inversión de Corea del

\footnotetext{
${ }^{6}$ Anahí Lovato es integrante de la Comisión Ejecutiva de la Cátedra Latinoamericana de Narrativas Transmedia.

${ }^{7}$ Concretamente, el storytelling es el arte de contar historias.

${ }^{8}$ KBS Korean Broadcasting System, empresa de radiodifusión pública de Corea del Sur. SBS Seoul Broadcasting Syste, una de las principales emisoras privadas de Corea del Sur. MBC Munhwa Broadcasting Corporation, canal de televisión terrestre de Corea del Sur.

${ }^{9}$ Están entre las más fuertes y destacadas, pero hay muchas más. Algunos ídolos tienen sus propias agencias.

${ }^{10}$ Conglomerado compuesto por más de 60 empresas de diversos ramos que tiene capacidad de exportación internacional. Su presencia mayoritaria está en Corea del Sur y Japón.
} 
Tabla 1. Plantilla para el diseño de narrativas transmedia

\begin{tabular}{|c|c|}
\hline \multicolumn{2}{|c|}{ Narrativa: mundo de la historia } \\
\hline Tema o conflicto & ¿Qué se quiere contar? \\
\hline Personajes y conexiones & ¿Quiénes son los protagonistas de la historia y cómo se vinculan? \\
\hline Escenarios y tiempos & ¿Dónde y cuándo se desarrolla la historia? \\
\hline Título & \\
\hline Género & \\
\hline Sinopsis & \\
\hline Elementos de la historia & Líneas narrativas o sub-tramas \\
\hline \multicolumn{2}{|r|}{ Experiencias } \\
\hline Audiencias/usuarios & $\begin{array}{l}\text { ¿Qué públicos se quieren alcanzar? ¿Dónde están? ¿Cómo y } \\
\text { cuándo consumen contenidos? }\end{array}$ \\
\hline Objetivos & ¿Qué se espera lograr? \\
\hline Participación & $\begin{array}{l}\text { ¿Qué se espera de la audiencia? ¿Cuánto podrán involucrarse en la } \\
\text { historia? }\end{array}$ \\
\hline Plataformas & $\begin{array}{l}\text { ¿Qué medios pueden permitir alcanzar dichas audiencias y } \\
\text { objetivos? ¿Qué lugar ocupa el mundo real (físico) en el desarrollo } \\
\text { de la historia y en las experiencias de usuario? }\end{array}$ \\
\hline \multicolumn{2}{|r|}{ Plataformas } \\
\hline \multicolumn{2}{|l|}{$\begin{array}{l}\text { Digital/analógica } \\
\text { Online/Offline }\end{array}$} \\
\hline Historia & $\begin{array}{l}\text { ¿Qué elementos del mundo de la historia o líneas narrativas se } \\
\text { desarrollarán aquí? }\end{array}$ \\
\hline Experiencia & ¿Qué podrán hacer los usuarios en esta plataforma? \\
\hline \multicolumn{2}{|l|}{ Remisiones entre plataformas y líneas narrativas } \\
\hline & Ejecución \\
\hline $\begin{array}{l}\text { Plataformas y servicios web existentes } \\
\text { Plataformas y servicios web que deben ser creados } \\
\text { Equipo técnico profesional } \\
\text { Rol } \\
\text { Conocimientos y habilidades } \\
\text { Cronograma de lanzamiento de piezas }\end{array}$ & \\
\hline
\end{tabular}

Fuente: Lovato (2018)

Sur y la Fundación Surcoreana para el Intercambio Cultural Internacional, 11 mil 600 millones de dólares.

A cada estrella se le conoce como idol (ídolo), en los procesos de producción se le construye una imagen única que los convierte en marca y a su vez, al ser parte de un grupo, el grupo en sí mismo también es una marca. "Los ídolos de $K$-рор se prepararán fuertemente por horas y por años antes de debutar. En el $K$-pop no hay nada al azar, todo está previsto. El $K$-pop es una marca y un orgullo nacional" (Televisa, 2015).

El K-pop es el término general para la música producida industrialmente en Corea del Sur, abarca los géneros del dance, pop, baladas, tecno, rock y hip hop. Después de los teléfonos inteligentes y los automóviles, el K-pop es considerado la exportación más conocida de Corea del Sur. En 2016 las ventas de esta industria alcanzaron un record de 4 mil 700 millones de dólares en ventas y el negocio en el extranjero contribuyó con más de 930 millones de dólares al Producto Interno Bruto del país

$[\ldots]$

El K-pop ingresó al mercado de la música japonesa con el cambio de siglo y pasó de ser un estilo musical a una subcultura entre los 
adolescentes y adultos jóvenes del Este y Sureste de Asia. El mercado de música pop asiática estuvo dominado por primera vez por una oleada de grupos coreanos como la boy band TVXQ que ofreció 65 conciertos en Japón entre 2006 y 2012 con una asistencia de 700 mil fanáticos y vendió más de 6.3 millones de álbumes. El salto definitivo a la fama mundial fue en 2012 con el Gangnam style del rapero PSY, la primera canción de $K$-pop en alcanzar los primeros lugares en las listas de popularidad de Estados Unidos y Europa. Las empresas discográficas del $K$-pop reclutan a adolescentes que pasan años de preparación antes de su presentación pública, la mayoría en boy bands o girl bands. Estos artistas se distinguen por sus coreografías complejas, voces melódicas, presentaciones muy producidas y un estilo aegyo (lindo, en coreano). Según expertos de la industria musical el éxito de $K$-pop se debe a la alta calidad del contenido, su bajo costo en comparación con la oferta occidental y al énfasis que hacen las disqueras en atender a los fanáticos. Uno de sus eventos de promoción más grande es el $K C O N$, una convención organizada por el conglomerado surcoreano $C J$ que tiene ediciones en París, Ciudad de México, Abu Dhabi, Sídney, Tokio y Los Ángeles: esta última fue la mayor, con una asistencia de 85 mil fans en 2017. Directivos de la industria opinan que otro de los motores de su alcance global han sido las redes sociales especialmente YouTube donde el $80 \%$ de las reproducciones de sus videos son desde el extranjero. Oficiales coreanos calculan que el $10 \%$ del turismo que visita el país lo hace exclusivamente por el fenómeno Hallyu que ha convertido a Corea del Sur en el líder de tendencias culturales en el Este asiático superando a Japón (Televisa, 2018).

En una nota publicada en 2018 por la revista VICE, Santos Cheryl señala que según estadísticas de Spotify el aumento en streams del K-pop entre 2016 y 2017 en México fue de $358 \%$ y en Latinoamérica de $298 \%$. En los cinco primeros lugares están: BTS, EXO, Black and Pink, Big Bang y Monsta X.
Como se vio en la lista anterior, BTS se encuentra en el primer sitio. Cabe decir que el grupo no es el único con fama mundial, hay otros de tradición y calidad, sin embargo BTS es el caso más claro de éxito transmedia en los últimos dos años. Por ejemplo, una muestra de su popularidad es que al rastrear a $B T S$ en el motor de búsqueda Google, este arroja, en 0.59 segundos, cerca de 89 millones 300 mil resultados. En contraste, aplicando la misma acción con Big Bang, grupo de fama y tradición, el resultado es de 4 millones 700 mil, en 0.66 segundos.

BTS significa Bangtan Boys o Bulletproof Boy Scouts (chicos a prueba de balas). Los integrantes son siete: RM (rapero y líder del grupo), Jin (cantante), Suga (rapero), J-Hope (rapero y bailarín), Jimín (cantante y bailarín), V (cantante) y Jungkook (cantante principal, bailarín y el integrante más joven del grupo). Como en todos los grupos de $K$-pop, cada elemento tiene una identidad propia y talentos diferentes que están articulados para complementarse en el concepto que el grupo representa.

Los colores oficiales de BTS son blanco y negro. Los géneros musicales incluidos en su concepto musical son Hip Hop, Rhythm and Blues y K-pop. Debido a su música y cuidadosos videoclips que combinan rap, baladas de amor y letras que hablan de lo que enfrentan y viven los jóvenes, BTS ha logrado empatizar con el público y a la vez diferenciarse de otros grupos de K-pop.

El proyecto de la banda nació en 2010 cuando Bang Shi Hyuk, propietario de la agencia de talentos Big Hit Entertainment, escuchó cantar a RM y firmó un contrato con él; los otros seis elementos fueron llegando poco a poco. La preparación antes del debut duró más de dos años. El 12 de junio de 2013 publicaron su primer sencillo llamado 2 Cool 4 Skool; su presentación formal fue al siguiente día en el programa $M$ ! Countdown ${ }^{11}$. En septiembre de ese año apareció su primer EP Oh, Are You Late Too? y también se presentó el primer reality del grupo, Rookie King. Su primera actuación fuera de Corea del Sur fue en Tailandia, en ese mismo año; meses más adelante tuvieron su primer concierto en Japón. A inicios de 2014 salió a la venta su mini álbum Skool Luv Affair.

\footnotetext{
${ }^{11}$ Programa de música surcoreano que se transmite por Mnet, es en vivo y sale al aire los jueves por la tarde. Inició en 2004 y ha tenido en su foro numerosos artistas de $K$-pop.
} 


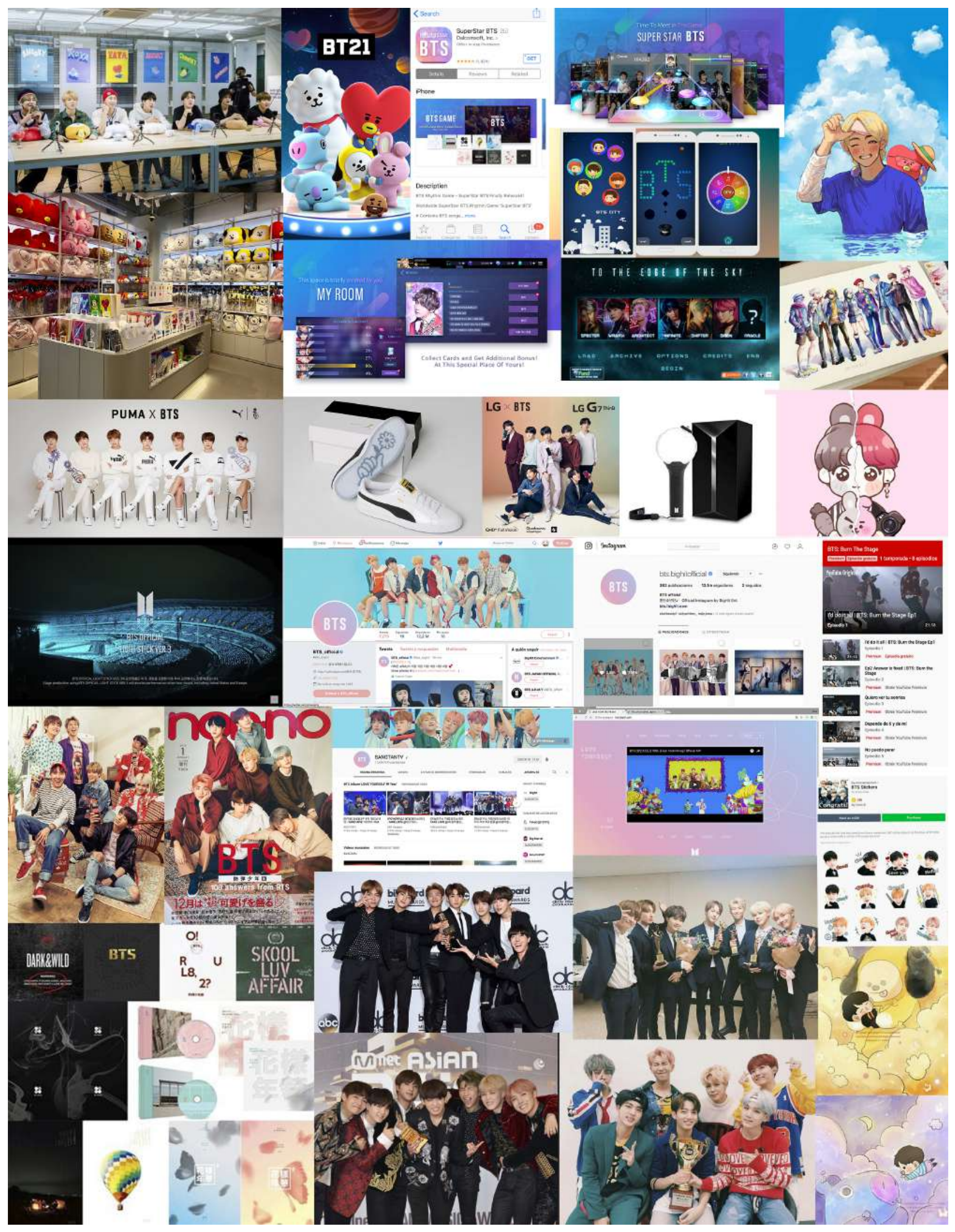

Figura 1. Impacto de BTS a través de imágenes 
Debido a su éxito en Japón, desde 2014, el grupo lleva una carrera paralela ahí y han publicado dos álbumes de estudio, seis sencillos y tres videos. A finales de ese año, la banda viajó a Estados Unidos con el objetivo de producir un disco nuevo y grabar su segundo reality: American Hustle Life. En el mes de agosto salió su primer disco completo de estudio, Dark \& Wild. En 2015 sus fans fueron aumentando y las entradas a sus conciertos internacionales también empezaron a agotarse. En ese año apareció el EP The most beautiful Moment in Life, Part 1, meses adelante salió la parte dos y la trilogía se cerró con un álbum especial.

Los fans de BTS se llaman a sí mismos ARMYS, acrónimo de Adorable Representative M.C. ${ }^{12}$ for Youth; también significa ejército, en inglés. Para los chicos del grupo, sus fans representan un ejército que incasablemente trabaja por ellos. En octubre de 2016 salió su segundo álbum de estudio, titulado WINGS. El disco entró a la lista Billboard 200 en el puesto número 26. La canción Fire logró, de manera simultánea, colocarse en el primer sitio en todas las listas musicales de Corea del Sur. A inicios de 2017 publicaron una nueva edición del disco Wings: You Never Walk Alone. Para el 10 de abril del 2017 BTS fue nominado en la categoría de los premios Billboard Music Awards Top Social Artist. ARMYS de todo el mundo votaron y llevaron al triunfo a su grupo, superando a artistas como Justin Bieber, Selena Gómez y Ariana Grande. A finales de 2017 el grupo lanzó su quinto mini álbum Love Yourself Here. El primer sencillo que se promocionó fue $A D N$ y en el mismo mini álbum se incluyeron colaboraciones con el dueto The Chainsmokers y el D.J. Steve Aoki. Canciones de este disco han liderado por semanas diversas listas de popularidad.

El grupo no ha cesado de romper récords desde que empezó. A la fecha ha recibido numerosos premios, buenas críticas y comentarios de la prensa especializada y del público. En julio de 2017 se anexó un nuevo acrónimo en la versión en inglés Beyond the Scene y se creó un nuevo logotipo. La empresa que representa al grupo, dijo que detrás de la nueva identidad de marca se asienta la noción "proteger a la juventud del prejuicio"13. Para la empresa de entretenimiento, BTS se mueve hacia adelante, persiguen sus sueños en lugar de

\footnotetext{
${ }^{12}$ Para los raperos, el término significa "maestro de ceremonias".

${ }^{13}$ En julio de 2018 la agencia Big Hit de BTS recibió, por su nuevo diseño de logotipo, el premio If Design Award, en la categoría de Identidad Corporativa/Marca. El evento se llevó a cabo en Alemania.
}

estancarse en la realidad. El nuevo diseño muestra a ARMYS conociendo a $B T S$ gracias a las puertas abiertas.

Con su imagen sociable, el apoyo y trabajo de sus fans, el grupo ha logrado posicionarse de excelente forma. Algunas de las cifras relevantes en este sentido son: 1) 14 millones de seguidores en Twitter (@BTS_twt) y en V LIVE. 2) En Instagram llegan a casi nueve millones de seguidores. 3) Más de 700 mil personas están inscritas en su Fan-café (@btsfancafes). Un detalle llamativo es que en 2017 se convirtieron en el primer grupo de $K$-pop surcoreano en tener su propio emoticono en Twitter además de ser los ídolos más mencionados en la red social durante 2017. Su página oficial de Facebook BTS (@ bangtan.official) tiene $6,699,824$ seguidores y su canal de YouTube BANGTANTV tiene $8,174,568$ seguidores.

Desde su debut han aparecido en casi 50 programas de la televisión internacional, en cinco reality shows (YouTube Red y V LIVE) y 19 programas de radio. Entre sus giras, conciertos y festivales en Asia, Europa, Medio Oriente y América se contabilizan 111 conciertos entre 2014 y 2017.

"De acuerdo con datos proporcionados por YouTube, en 2017, la cifra del consumo de Brasil, México, Argentina, Perú, Chile, Colombia, Ecuador, Venezuela y Bolivia, solamente de los videos de BTS, llega a 1,116,573,173 de views" (Santos, 2018).

En una gira de promoción por Estados Unidos, se presentaron en algunos programas de variedades de la televisión de ese país, por ejemplo: The Ellen DeGeneres Show, The Late Late Show with James Corden, y Jimmy Kimmel Live!. De esta manera el medio del espectáculo los empezó a identificar. Su calendario de giras 2018 incluye Corea del Sur, Canadá, Holanda, Reino Unido, Alemania, Francia y diversas ciudades de Estados Unidos. De acuerdo a la información proporcionada por la agencia Big Hit Entertainment, casi el $50 \%$ de sus fechas están agotadas.

Entre 2015 y 2018 BTS ha sido imagen y modelado para 20 marcas internacionales, entre ellas: Coca Cola, LG, PUMA, Lotte Duty Free, Yahoo Wi Fi, SK Telecom y UNICEF and BTS “Love my Self”, entre otras.

El grupo se ha hecho acreedor a 113 premios $y$ reconocimientos nacionales e internacionales. El más relevante es el Premio Billboard Music Awards en la categoría 
Tabla 2. Análisis del caso BTS con base en la Plantilla para el diseño de narrativas transmedia

\begin{tabular}{|c|c|}
\hline \multicolumn{2}{|r|}{ Narrativa: mundo de la historia } \\
\hline Tema o conflicto & $\begin{array}{l}\text { Historias de jóvenes para jóvenes a través de ídolos/héroes que representan un apoyo moral, un amigo } \\
\text { cercano para los fans. }\end{array}$ \\
\hline Personajes y conexiones & $\begin{array}{l}\text { Los siete integrantes del grupo: RM, Jin, Suga, J-Hope, Jimín, V y Jungkook. Cada uno tiene personalidad } \\
\text { y talentos únicos, que al unirse y formar el conjunto, hacen de } B T S \text { un grupo con identidad y estrategias } \\
\text { propias para liderar el mundo del K-pop. }\end{array}$ \\
\hline Escenarios y tiempos & $\begin{array}{l}\text { Escenarios reales: conciertos, presentaciones en programas de televisión, reuniones con fans. Escenarios } \\
\text { virtuales: juegos de video, aplicaciones, sesiones live, reality shows. Época contemporánea en comunicación } \\
\text { sincrónica y asincrónica a través de distintos medios. }\end{array}$ \\
\hline Título & $\begin{array}{l}\text { Concepto creativo del grupo: "Bangtan Boys"; "Bulletproof Boy Scouts" (chicos a prueba de balas); "Beyond } \\
\text { the Scene". Identidad de marca: "Proteger a la juventud del prejuicio". }\end{array}$ \\
\hline Género & K-pop. \\
\hline Sinopsis & A través del discurso de jóvenes para jóvenes, "proteger a la juventud del prejuicio". \\
\hline Elementos de la historia & $\begin{array}{l}\text { Música y letras. Videos musicales. Reality Shows. Conciertos. Aplicaciones. Juegos de video. "En vivos" } \\
\text { con fans vía redes sociales. Encuentros con fans. }\end{array}$ \\
\hline \multicolumn{2}{|r|}{ Experiencias } \\
\hline Audiencias/usuarios & $\begin{array}{l}\text { Jóvenes de Asia, Europa, Medio Oriente, Norteamérica y América del Sur. Los contenidos se consumen de } \\
\text { manera sincrónica y asincrónica debido a que se difunden por Internet y los husos horarios de cada región } \\
\text { son distintos. Esto no implica ninguna complicación porque las audiencias conviven de forma natural con } \\
\text { esos medios. Los usuarios son hablantes de diferentes idiomas pero el inglés es la lengua que permite la } \\
\text { vinculación. }\end{array}$ \\
\hline Objetivos & $\begin{array}{l}\text { Crear comunidad e identidad ARMY. Apoyar a su grupo a través de todos los medios de comunicación en red } \\
\text { para mantenerlo en el liderazgo y romper récords. Tener proximidad con sus ídolos a través de los medios } \\
\text { que les permiten contacto directo/virtual (en vivos). Agradecer a sus ídolos por existir y responder con su } \\
\text { proyecto a las necesidades y entornos de la juventud mundial contemporánea. }\end{array}$ \\
\hline Participación & $\begin{array}{l}\text { Apoyo, amor y lealtad de los fans. Participación y protagonismo en innumerables interacciones a través de } \\
\text { las redes sociales. Creación y administración de clubes de fans y comunidades de seguidores. Construcción } \\
\text { de contenidos a través de las redes sociales; por ejemplo, fan-art. Fortalecimiento de la imagen y poder del } \\
\text { grupo. Consumo de todo tipo de productos BTS. Robustecimiento y legitimación del Hallyu. Su nivel de } \\
\text { involucramiento es las narrativas de BTS es muy alto debido a los medios que se usan para la difusión de los } \\
\text { contenidos. Hay una historia eje que nace del grupo y cientos o miles de historias paralelas que se construyen } \\
\text { de manera simultánea por los integrantes del grupo y por los fans. }\end{array}$ \\
\hline Plataformas & $\begin{array}{l}\text { Sitios web: Soompi, Koreaboo, Allkpop. Páginas y sitios oficiales del grupo y de la agencia de entretenimiento. } \\
\text { Aplicaciones: V LIVE. Redes sociales: Twitter, Instagram, Facebook, Pinterest, Kakao Talk. Otros sitios } \\
\text { web: YouTube. Todos los medios citados son soportes indispensables para que el contenido narrativo de BTS } \\
\text { llegue a sus audiencias. Fuera de Corea del Sur la única manera de acceder al contenido es vía Internet. }\end{array}$ \\
\hline \multicolumn{2}{|r|}{ Plataformas } \\
\hline Digital/analógica & Televisión digital, radio digital, Internet, video en streaming. \\
\hline \multicolumn{2}{|l|}{ Online/Offline } \\
\hline Historia & $\begin{array}{l}\text { Numerosas, cada sencillo, álbum, concierto, presentación y/o video, tienen un hilo narrativo, una temática que } \\
\text { distingue y aporta cada integrante del grupo, sin perder de vista la premisa original del conjunto: "historias } \\
\text { de jóvenes para jóvenes" y "proteger a la juventud del prejuicio". }\end{array}$ \\
\hline Experiencia & $\begin{array}{l}\text { Ser espectadores de los contenidos de radio y televisión nacional e internacional en los que se presenta el } \\
\text { grupo. Ser prosumidores en los medios en red. Construir comunidad, crear identidad, apoyar a su grupo y } \\
\text { consumir productos. }\end{array}$ \\
\hline $\begin{array}{l}\text { Remisiones entre plataformas y } \\
\text { líneas narrativas }\end{array}$ & $\begin{array}{l}\text { Todos los contenidos digitales están hipervinculados a través de hashtags. Se puede navegar para informarse, } \\
\text { conocer y también se puede construir contenido. }\end{array}$ \\
\hline \multicolumn{2}{|r|}{ Ejecución } \\
\hline $\begin{array}{l}\text { Plataformas y servicios web } \\
\text { existentes }\end{array}$ & Todas \\
\hline $\begin{array}{l}\text { Plataformas y servicios web que } \\
\text { deben ser creados }\end{array}$ & Ninguno \\
\hline Equipo técnico profesional & No aplica \\
\hline Rol & No Aplica \\
\hline Conocimientos y habilidades & No aplica \\
\hline $\begin{array}{l}\text { Cronograma de lanzamiento de } \\
\text { piezas }\end{array}$ & No aplica \\
\hline
\end{tabular}

Fuente: Lovato (2017) 
Top Social Artist; en el que BTS logró llevarse el mismo galardón dos años consecutivos: 2017 y 2018. El premio es otorgado por los votos de los fans, de los que lograron 300 millones en 2017 y 342 millones en 2018. Sus discos han ganado los premios Doble Platino, Premio Gold, Gold y Platino, en Japón y Estados Unidos.

El portal de noticias Soompi ${ }^{14}$ publicó, el 6 de enero de 2018, una nota firmada por Rossana 23 en donde se reproducen algunas apreciaciones del CEO de Big Hit Bang, Shi Hyuk, sobre el éxito del grupo.

Había imaginado a BTS como un grupo ídolo que era a la vez fuerte y con el que la gente pudiera identificarse [...] estábamos debatiendo qué tipo de grupo ídolo crear [...] ¿Qué tipo de héroe busca la juventud de hoy? No es alguien que predique dogmáticamente desde arriba. Por el contrario, parece que necesitan un héroe que les preste un hombro para apoyarse, incluso sin decir una sola palabra. No quería que fueran falsos ídolos [...] Quería crear un BTS que pudiera convertirse en un amigo cercano $[. .$.

Cuando estábamos formando BTS, resolvimos hacer un grupo que tuviera una influencia positiva [... ] Después de todo, los ídolos son ídolos. Un ídolo que tiene una influencia negativa es un ídolo falso. Pensamos que no debería haber ninguna glorificación del comportamiento delictivo o la intolerancia a la injusticia social en sus canciones, incluso sí solo está implícito. Resolvimos no hacer nada de eso incluso si pudiera parecer genial en ese momento [...]

Dado que decidimos que BTS serían cantantes que dijeran la verdad sobre la realidad, dijimos: 'Hablemos del dolor, y digamos que en vez de simplemente vivir pasivamente, debemos trabajar duro para superar los obstáculos. Ya sea que ganemos o que perdamos, es tener sueños lo que nos hace jóvenes' [...] Mi objetivo era que

\footnotetext{
${ }^{14}$ Soompi es uno de los sitios más grades y de mayor tradición que ofrece diversa información sobre la cultura de Corea del Sur; principalmente sobre K-pop y K-Dramas. El sitio trabaja con las más importantes agencias de entretenimiento de Corea y cuenta con una de las comunidades más grandes en Internet. https://www.soompi.com/es/
}

BTS se convirtiera en un artista importante en el mercado global. Han tenido un buen comienzo y espero lo mantengan y sigan creciendo (Rossana $23,2018)$.

Algunos datos más: BTS tiene línea de productos oficiales: discos, light sticks, calendarios, eslogan oficial en tela, guantes, bolsas, álbumes de fotos, cintas, dijes, llaveros, entre otros. Todos los productos se pueden importar y una forma para obtenerlos es por medio de las fans, quienes a través de los clubes organizan los pedimentos. También hay juegos de video y moda, pues los chicos son imagen de algunas marcas internacionales. Los fans tienen acceso, a través de aplicaciones, plataformas y video en streaming, a reality shows, conciertos, emoticonos para aplicaciones de chat y muchos productos más. La Figura 1 presenta algunas imágenes que ejemplifican lo descrito.

\section{Conclusión}

Sin duda el K-pop no es una moda pasajera, como algunos han sugerido: el fenómeno Hallyu va más allá de solo productos de entretenimiento. Dos décadas llevó lograr que el mundo volteara a mirar a aquella pequeña nación asiática que por años permaneció cerrada, ermitaña. El gobierno surcoreano pensó, decidió y diseñó un proyecto de conquista internacional para posicionar su imagen positivamente y abrir nuevos mercados internaciones. El Hallyu es uno de los casos de poder blando más claros del mundo contemporáneo y BTS es el grupo de $K$-pop con la imagen más reconocida y fuerte a nivel internacional.

Los chicos están en un buen momento a nivel profesional. No es casualidad que así sea: detrás del proyecto BTS hay un diseño que los distingue, porque en su narrativa transmedia cuentan historias específicas para sus pares generacionales, sus videos son traducidos a varios idiomas y publicados en tiempo real por redes sociales. Los integrantes del grupo no muestran una imagen misteriosa, sostienen mucha comunicación con sus fans y sus letras parecen honestas. En síntesis, BTS tiene una estrategia de comunicación en red cuidada, comprobadamente asertiva y exitosa para abonar al Hallyu como muestra de poder blando. 


\section{Referencias}

Kang, W. (2016). El Diccionario K-POP español. United States: New Ampersand Publising.

Lovato, A. (20 de Marzo de 2018). Academia.edu. Recuperado de https://www.academia.edu/32665461/Plantilla_par a_Dise\%C3\%B1o_de_Narrativas_Transmedia

Manocvich, L. (2005). El Lenguaje de los Nuevos Medios de Comunicación. Barcelona, España: Paidós.

Nye, J. (2004). Soft Power: The Means To Success In World Politics. New York: PublicAffairs.

Official, M. M. (11 de agosto de 2016). Lee Min Ho KCON LA 2016 Versión Completa [Subtitulado en español]. México. Recuperado de https://www.youtube.com/watc $\mathrm{h}$ ? $\mathrm{v}=$ G0DyQrwCIDo

Rossana23. (6 de enero de 2018). Soompi. Recuperado de https://www.soompi.com/es/2018/01/06/bang-shi-hy uk-comparte-el-secreto-del-exito-de-bts-y-su-maxim a-meta-para-el-grupo/

Ruiz, S. (2014). Las características de las narrativas transmedia. En F. Irigaray, Hacia una Comunicación Transmedia. 6o. Foro Internacional de Periodismo Digital. 1er Encuentro de Narrativas Transmedia (págs. 97-104). Rosario, Argentina: Universidad Nacional de Rosario. Recuperado de http://www.acuedi.org/ddata/1 1325.pdf

Santos, C. (11 de enero de 2018). VICE. Recuperado de https://i-d.vice.com/es/article/9kngb3/k-pop-latinoa merica-2017

Scolari, C. (2013). Narrativas Transmedia. Cuando todos los medios cuentan. Barcelona, España: Centro Libros PAPF, S. L. U.

Simón, R. (2015) Repercusiones sociales de género de la ola coreana (Hallyu). Trabajo de fin de grado, estudios de Asia Oriental, Facultad de traducción y de interpretación, UAB. Recuperado de https://ddd.uab.cat/pub/tfg/2015/tfg_25063/Simon_E iras_Raquel_TFG_GEAO_2014-15.pdf

Televisa, N. (30 de Julio de 2015). K-Pop da a Corea del Sur mil 600 mdd. México. Televisa. Recuperado de https: $/ /$ www.youtube.com/watch?v=xwq9jbFYbqk

Televisa, N. (13 de marzo de 2018). El poder del K-Pop en Corea del Sur. Foro Global. El K Pop es un arma importante en Corea del Sur, como parte de una estrategia gubernamental. México. Recuperado de https: //www.youtube.com/watch?v=HjEWoGRNZaE

Torres, M. (2005). El Poder Blando: ¿Una alternativa a la fuerza militar? Política y Estrategia (100), 14. Recuperado de https://www.upo.es/export/portal/com /bin/portal/upo/profesores/mrtorsor/profesor/1214213 043213_el_poder_blando._una_alternativa_a_la_fuerz a_militar.pdf
Vargas, X. (Julio de 2015). La globalización de productos culturales: Un Análisis. REDES- Revista hispana para el análisis de redes sociales, 26, 124-148. 